\title{
Efficient Detection of Aerosols Above Clouds Utilizing GCOM-C/SGLI Data
}

\author{
Sonoyo Mukai ${ }^{1, ~ *, ~ M a k i k o ~ N a k a t a ~}{ }^{2}$, Toshiyuki Fujito ${ }^{1}$, Itaru Sano ${ }^{3}$ \\ ${ }^{1}$ School of Applied Information Technology, The Kyoto College of Graduate Studies for Informatics, Kyoto, Japan \\ ${ }^{2}$ Faculty of Applied Sociology, Kindai University, Higashi-Osaka, Japan \\ ${ }^{3}$ Faculty of Science and Engineering, Kindai University, Higashi-Osaka, Japan
}

Email address:

s_mukai $a$ kcg.ac.jp (S. Mukai)

${ }^{*}$ Corresponding author

\section{To cite this article:}

Sonoyo Mukai, Makiko Nakata, Toshiyuki Fujito, Itaru Sano. Efficient Detection of Aerosols Above Clouds Utilizing GCOM-C/SGLI Data. International Journal of Environmental Monitoring and Analysis. Vol. 8, No. 5, 2020, pp. 170-180. doi: 10.11648/j.ijema.20200805.16

Received: October 4, 2020; Accepted: October 19, 2020; Published: October 26, 2020

\begin{abstract}
This work aimed at detection of aerosols above clouds (AAC). It has been known that AAC has significant potential to change the global radiation budget, namely plays an important role in elucidating climate change. First we examined the advantages of multichannel data from near-UV to thermal infrared (IR) including polarization channels at red and near-IR collected using the GCOM-C/SGLI. The near-UV data at $0.38 \mu \mathrm{m}$ and $0.41 \mu \mathrm{m}$ not only detected absorbing aerosols such as biomass burning aerosols (BBA) or mineral dust (DUST), but were also used to distinguish between BBA and DUST with short wavelength IR measurements at $1.63 \mu \mathrm{m}$. Because understanding aerosol types facilitates subsequent aerosol characterization, classification algorithms for aerosol types have been dealt with since the previous work. Discriminant verification was performed using ground measurements from NASA/AERONET and practically examined in a case of large forest fire. Then the detection of optically thick clouds was challenged in a similar way to aerosol classification in order to lead such a final goal of this work as detection of aerosols above clouds. Subsequently some scenes concerned with DUST type aerosols or BBA ones above water clouds were detected using GCOM-C/SGLI radiance or polarization measurements, respectively, and validated with Terra/MODIS products.
\end{abstract}

Keywords: BBA (Biomass Burning Aerosol), DUST, Multichannel Satellite Data, Near-UV, Color Ratio, Polarization

\section{Introduction}

This work is an application of our aerosol type classification algorithm mentioned in the previous work [1] to the recent Japanese mission GCOM-C/SGLI measurements. The importance of aerosols is further recognized in reference to global warming and climate change being more serious and imminent. From many research studies, it is well known that aerosols directly and indirectly have various effects on the climate [2-5]. They have significant potential to change atmospheric circulation fields through changes in the radiation budget [6]. Aerosols are said to have negative effects on surface temperature and positive effects on cloud cover [7, 8]. On the other hand, the fifth Intergovernmental Panel on Climate Change (IPCC) report illustrates the warming effect of black carbon aerosols versus the cooling effect of other types of aerosols $[9,10]$. Therefore, the accurate detection of aerosol types has become an urgent subject to understand global climate problems. Additionally, they have an effect on each other. For example, large forest fires have increased due to global warming and climate change, while at the same time the warming effect type biomass burning aerosols (BBA) are caused by the forest fires or agriculture burning [11-13]. Therefore, this work focuses on the efficient detection of BBA. Moreover, mineral dust aerosols (DUST) are the most abundant aerosols in both quality and quantity [14-17].

It is well known that not only BBA and DUST aerosols, but all types of aerosols have significant influences on factors such as air quality, global climate change, local environmental risk, and human and biological health [18-20]. Aerosol remote sensing from satellites has been occurring for more than 20 years. The Moderate Resolution Imaging Spectroradiometer (MODIS) is the most notable and valuable space-based instrument for aerosol observations [21]. MODIS has been operating on Terra and Aqua missions since 1999 and 2002, 
respectively. Many kinds of products have been obtained from MODIS measurements with respect to the land, ocean, atmosphere, and cryosphere, and their data are available for download (modis.gsfc.nasa.gov/data) [22]. Historically, the Total Ozone Mapping Spectrometer (TOMS) onboard the Nimbus-7 satellite in November 1978 played an important role in aerosol remote sensing. The TOMS demonstrated that ultraviolet (UV) wavelengths were effective for the detection of absorbing aerosols such as carbonaceous aerosols or mineral dust [23]. Such observations continue via the Ozone Monitoring Instrument (OMI) onboard the Aura satellite [24]. Furthermore, an innovative instrument for aerosol remote sensing is Polarization and Directionality of the Earth's Reflectances (POLDER). POLDER is a passive optical imaging radiometer/polarimeter developed by CNES and it has demonstrated the usefulness of polarization information for the analysis of aerosols [25], clouds, and aerosol above cloud (AAC) systems [26]. The studies by Waquet et al. have pointed out that the direct $\mathrm{AAC}$ radiative forcing cannot be ignored and the direct aerosol radiative forcing in cloud scene should be considered in estimation of the global radiation budget [26-28].

The Japanese satellite Global Change Observation Mission-Climate (GCOM-C) was launched on December 23 in 2017, and mounted with only the Second Generation Global Imager (SGLI) multi-spectral sensor, which has 19 channels that encompass the near-UV $(0.38 \mu \mathrm{m})$ and violet $(0.41 \mu \mathrm{m})$ wavelengths and two polarization channels in the red $(0.67$ $\mu \mathrm{m})$ and near-IR $(0.86 \mu \mathrm{m})$ wavelengths. The previous work mainly used the measurements from ADEOS-2/GLI \& POLDER-2 observed from April to October in 2003. The ADEOS-2 satellite carried Global Imager (GLI) multi-spectral sensor and the polarization sensor POLDER-2. It has been well that POLDER is a useful instrument for aerosol and cloud remote sensing. In that sense, GCOM-C/SGLI has the combined function of ADEOS-2/GLI and ADEOS-2/POLDER-2. Using the advantageous features of SGLI, we intend to develop algorithms for the classification of aerosol types and connect further to efficient aerosol retrieval of aerosols above clouds. Because aerosols not only modify cloud properties, but also aerosols above clouds have significant potential to change the radiation budget.

Aerosol characteristics can be represented using many kinds of parameters. The spectral aerosol optical thickness $\operatorname{AOT}(\lambda)$ at wavelength $\lambda$ is the basic parameter [29]. Several other aerosol properties such as size distribution and refractive index are derived from the AOT $(\lambda)$ and angular dependency of scattered radiance [30]. The quantity and quality of aerosols change from time to time depending on the location. Therefore many parameters have to be prepared for the retrieval of the optimized aerosol characteristics, especially at a global scale. Too many parameters are excessive for numerical analysis, and a reasonable simplification for aerosol models is expected. The classification of aerosol types facilitates subsequent aerosol retrieval [31]. In addition, the aerosol type is a key factor in understanding global climate problems. According to the automatic classification of accumulated NASA/AERONET data, atmospheric aerosols are classified into six categories, which are biomass burning (BB), rural (RU), continental pollution (CP), dirty pollution (DP), desert dust (DD), and polluted marine (PM) [32]. These aerosol classifications have been substantially evaluated and are useful for aerosol remote sensing. Improvements to the algorithm are ongoing [33-35] and the present study is a preliminary step in this, namely, developing algorithms for the rapid and simple distinction of the BB and DD aerosol types from the other types.

The rest of this paper is organized as follows. Type classification of aerosols over land is treated using the features of GCOMM-C/SGLI measurements in section 2. In subsection 2.1, the similarity and diversity of the algorithms for distinguishing aerosol type between the present study and the previous one due to the observation performance of SGLI and GLI are described. After examination of the updated algorithms using the SGLI radiance measurements of R (0.38), $\mathrm{R}$ (0.41) and $\mathrm{R}$ (1.63) on a global scale, the aerosol classification criteria are obtained. In subsection 2.2, the obtained aerosol distinction criteria are verified. First, the biomass-burning episode that happened in North West Coast around Canada-United State border on September 18, 2020 is taken up to practically validate BBA type aerosol identification. Next, discriminant verification is performed using ground measurements from NASA/AERONET.

In section 3 , the selection of aerosols above clouds (AAC) is challenged. First, in subsection 3.1, the detection of optically thick clouds is considered in a similar algorithm as mentioned in section 2. Some instances for detection of DUST above optically thick clouds are examined based on DDI using SGLI measurements in subsection 3.2. Further possibilities for detection of BBA above clouds are examined using polarization information in subsection 3.3. Note that the practical results of aerosols above clouds are compared with Terra/MODIS products through NASA/World View. In order to capture the behavior of aerosols transported above water clouds, some case studies of AAC distribution are shown on the global scale in subsection 3.4.

Finally, the obtained results in this study are summarized, and then future prospects aiming further development of this work are given in section 4 .

\section{Classification of Aerosol Type Based on GCOM-C/SGLI Measurements}

\subsection{Utilization of Near-UV Data}

The TOMS showed that UV data were effective for the detection of absorbing aerosols such as carbonaceous aerosols or mineral dust $[23,36,37]$. Our previous works [1, 38] were also based on a similar concept in the TOMS-AI (aerosol index). In this study, to follow on from previous works, we named the following index AAI (absorbing aerosol index):

$$
\mathrm{AAI}=\mathrm{R}(0.41) / \mathrm{R}(0.38) .
$$

The variable $\mathrm{R}$ in Eq. (1) represents the satellite observed 
reflectance value at the near-UV $(0.38 \mu \mathrm{m})$ and violet $(0.41 \mu \mathrm{m})$ wavelengths. It is added to avoid ambiguity, whereby the definition of our AAI differs from those employed by the TOMS or the Global Ozone Monitoring Experiment (GOME) [39] in the formula and the reference channels. They employed a shorter wavelength $(0.34 \mu \mathrm{m})$ than that used in Eq. (1), and our index AAI has a simpler form, with only the ratio of the reflectance.

Figures $1 \mathrm{a}$, and $1 \mathrm{~b}$ present observational channels and band performance of VN (Visible and Near infrared) to SW (Short Wavelength infrared) for SGLI, and those of GLI, respectively. The item "IFOV" is an abbreviation of Instantaneous Field of View. From Figure 1, it is evident that both sensors have similar wavelength channels because SGLI is a successor of GLI. The AAI, as defined in Eq. (1), can be applied to GCOM-C/SGLI in 2017 as was done for ADEOS-2/GLI in 2002. In other words, our previous work is a bridge from GLI to SGLI for aerosol retrieval.
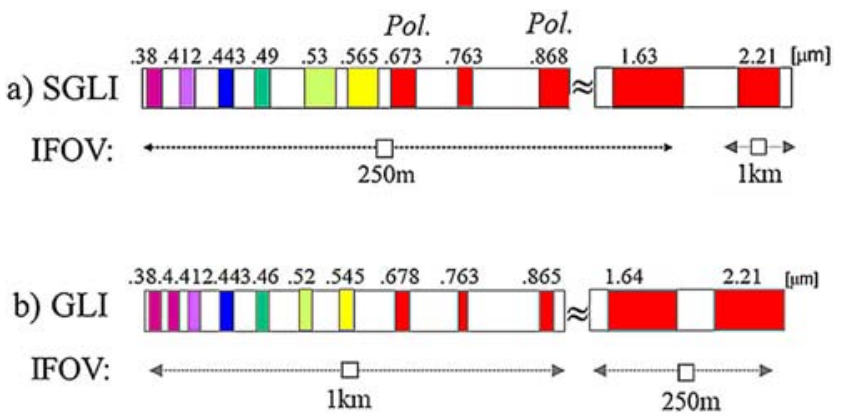

Figure 1. Band performance of observational channels from VN (Visible and Near infrared) to SW (Short Wavelength infrared) of GCOM-C/SGLI, 2017 and ADEOS-2/GLI, 2002 in Figures 1a and 1b, respectively.

From the select data observed by ADEOS-2/GLI, we have drawn the results that absorbing aerosols such as BBA with $\mathrm{AAI} \geq 0.83$ and DUST with $\mathrm{AAI} \geq 0.90$ can help to distinguish them from other types of aerosols in the previous work. The term BBA represents biomass burning aerosols as previously defined. The AAI index is also available for the GCOM-C/SGLI data, and the same values have been obtained as a threshold of AAI for BBA as well as DUST in this study, using global SGLI data as shown below.

In order to separate the BBA from the DUST in the domain AAI $\geq 0.9$, another index was required. The shortwave infrared wavelength-channels were used to detect the dust aerosols $[40,41]$. Therefore, the band with $2.21 \mu \mathrm{m}$ of GLI was introduced in the previous work [1]. However, in reference to the performance shown in Figure 1, the $1.63 \mu \mathrm{m}$ band seems to be better than the 2.21 one in the case of SGLI [42]. The following reflectance ratio (R) at a wavelength of $1.63 \mu \mathrm{m}$ to that of $0.38 \mu \mathrm{m}$ is adopted here as an updated DDI (dust detection index);

$$
\mathrm{DDI}=\mathrm{R}(1.63) / \mathrm{R}(0.38) .
$$

Figure 2 presents histograms and cumulative frequencies of AAI at every interval of AOT $(0.50 \mu \mathrm{m})$ as $[0.0,0.1],[0.1,1.0]$, and $[1.0,3.0]$ in the top, middle and bottom, respectively, where $\mathrm{N}$ represents the total number of available measurements of
GCOM-C/SGLI/L2. The SGLI data for BBA are selected over BBA-domain areas such as the Amazon, South Africa, and Siberia from May 1 to October 15 in 2018 and May 1 to August 26 in 2019. The data for DUST are selected over the Sahara Desert from May 1, 2018 to August 26, 2019. The total amount of data is enough for statistical processing.

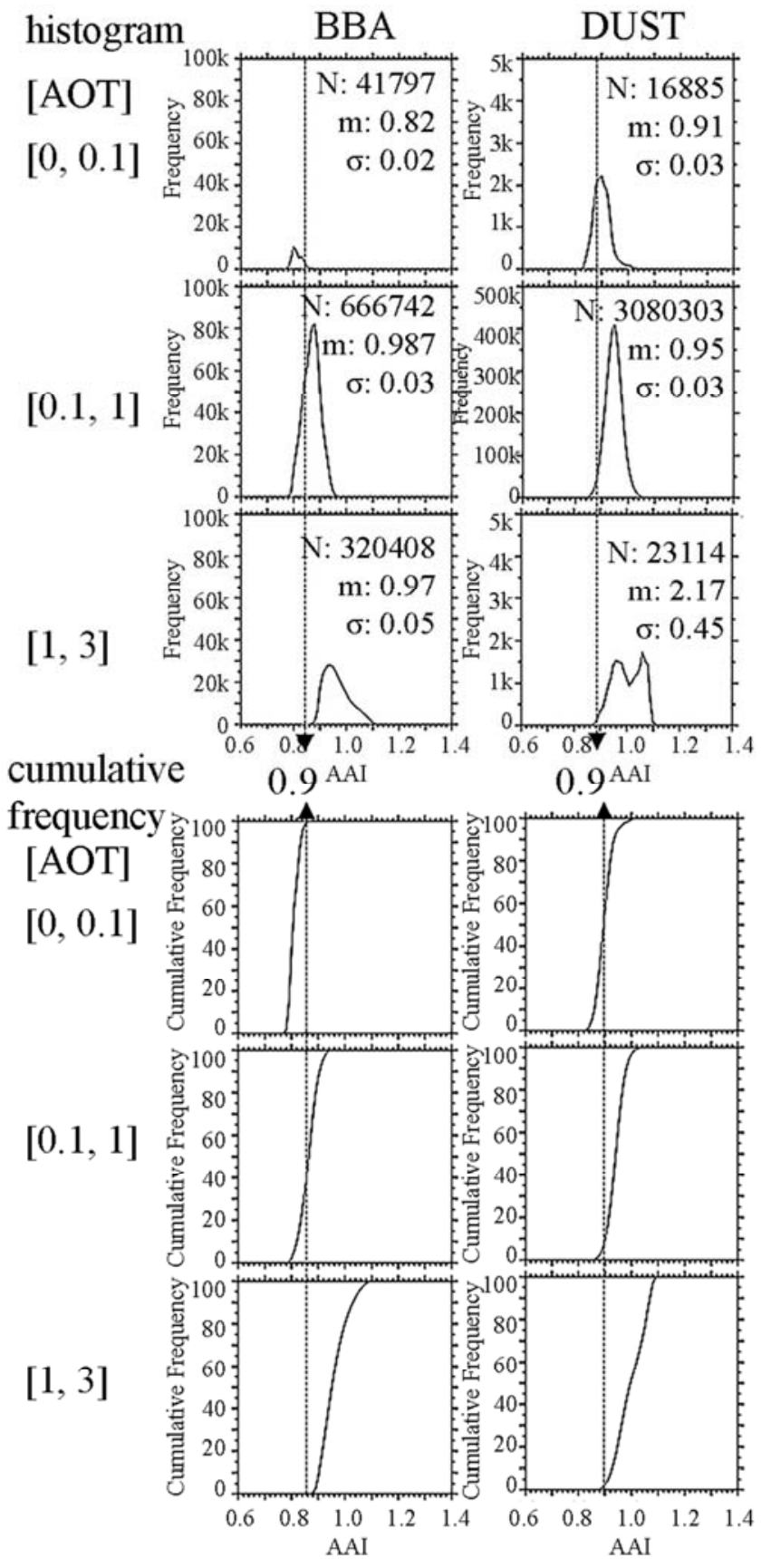

Figure 2. Histograms and cumulative frequencies of AAI at every interval of AOT as [0.0, 0.1], [0.1, 1.0], and [1.0, 3.0] in the top, middle and bottom, respectively, where $N$ represents the total number of available SGLI data in the target areas.

Figure 3 is the same as Figure 2 but for DDI. It is found from Figures 2 and 3 that the mean $(\mathrm{m})$ and standard deviation $(\sigma)$ values of the histogram were changed with the AOT intervals. From the cumulative frequency, AAI $\geq 0.83$ in the 
domain AOT $\geq 1.0$ accounted for $99 \%$ of the total for BBA. Similarly, AAI $\geq 0.9$ accounted for $97 \%$ of the total for DUST. Furthermore, in respect to DUST, it was mentioned that desert reflection alone was approximately at $0.83 \leq \mathrm{AAI}<0.89$, desert reflection with DUST was at $0.89 \leq \mathrm{AAI} \leq 0.9$, and DUST scattering alone was at $\mathrm{AAI} \geq 0.9$. However, more data besides the ones from Sahara are necessary to draw this conclusion in detail. Nevertheless, we conclude that BBA, and DUST are detected at $\mathrm{AAI} \geq 0.83$, and $\mathrm{AAI} \geq 0.9$, respectively. This conclusion coincided with the GLI case treated in the previous work [1]. The values of DDI for BBA were approximately lower than 1.1 at low AOTs and apparently were decreasing with the AOT until AOT=3. It was concluded that the BBA acquired DDI values lower than 1.1. It was found that almost all the DUST (99\%) acquired DDI values $\geq 1.1$ denoted by the dotted arrow in Figure 3. Simply speaking, the values of DDI were greater than 1.1 for Dust. We concluded that $\mathrm{DDI}=1.1$ was the threshold value to distinguish between BBA and DUST.

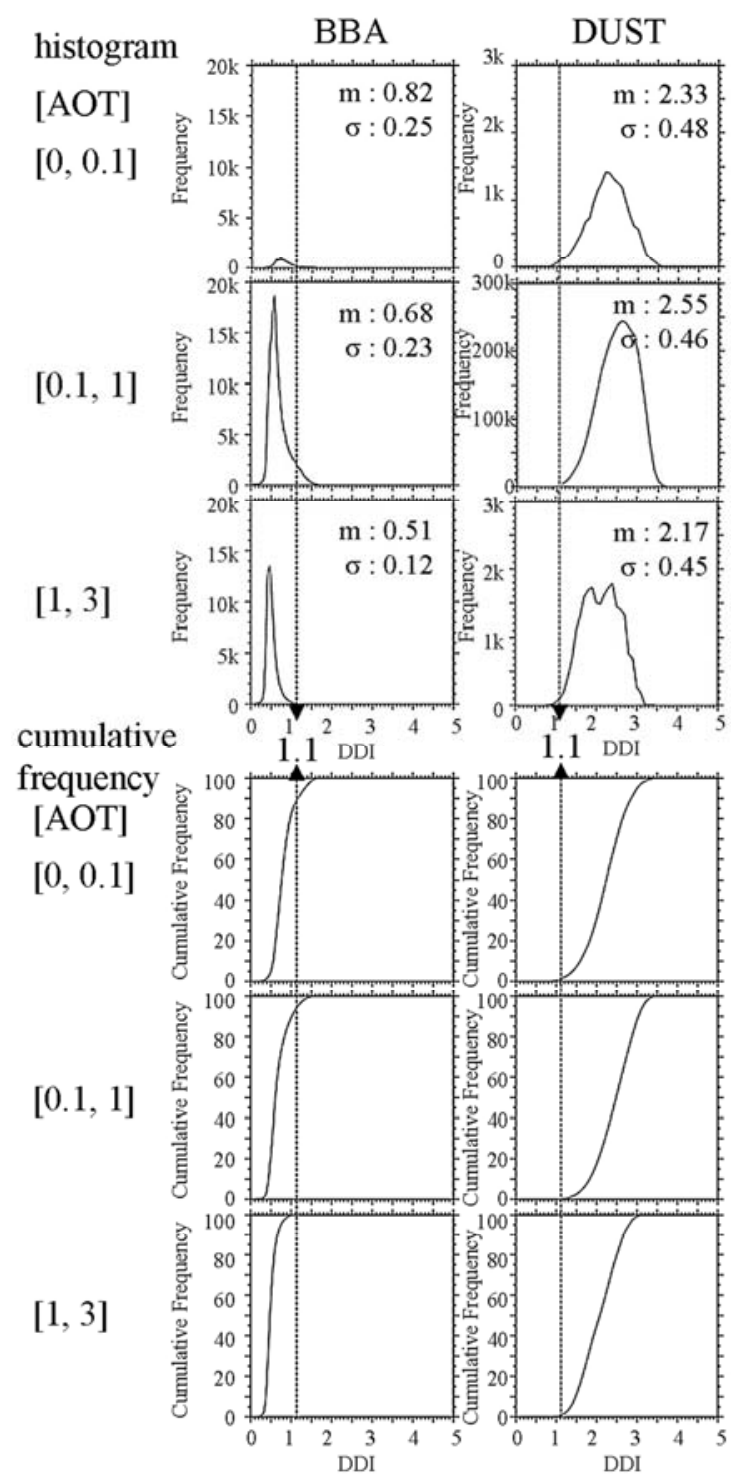

Figure 3. The same as Figure 2 but for DDI.
As a result, an aerosol type discrimination chart has been obtained in the 2-dimensional coordinates of the AAI and DDI as shown in Figure 4, based on three channels, 0.38, 0.41, and $1.63 \mu \mathrm{m}$ of GCOM-C/SGLI measurements. The dark yellow, red, and cyan colors represent DUST, BBA, and other types of aerosols, respectively.

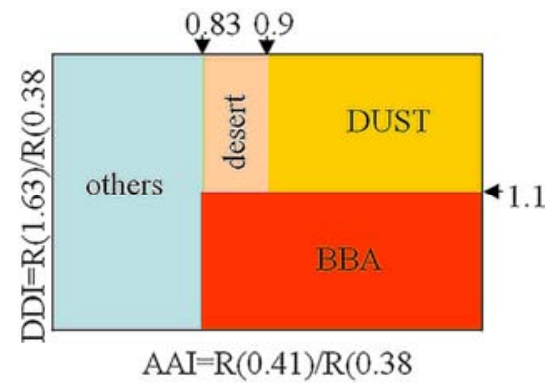

Figure 4. Aerosol type discrimination chart in 2-dimensional space derived from SGLI measurements. The horizontal and vertical axes denote the AAI and DDI values, respectively.

\subsection{Verification and Validation of the Aerosol Type Distinction}

Aerosol type classification algorithms derived in the previous section from SGLI/level-2 global data of radiance are practically examined in the case of a large forest fire in North West Coast around Canada-United State border that happened on September 18, 2020. The image on the left in Figure 5 presents the color composite image enlarged around the area in question and the figure on the right is the geometrical map. The white rectangle in this map indicates the approximate satellite image position on the left side. It is found from Figure 5 that the color composite image clearly shows that the forest fire occurred in the mountains along the west coast, caused heavy smoke, i.e. biomass burning aerosols (BBA) colored by smoky gray, and spread eastward.

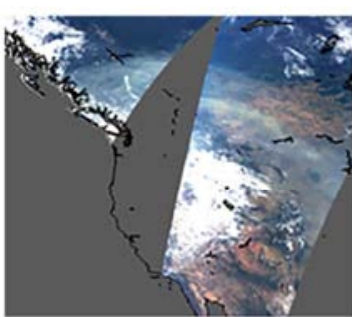

Color composite image

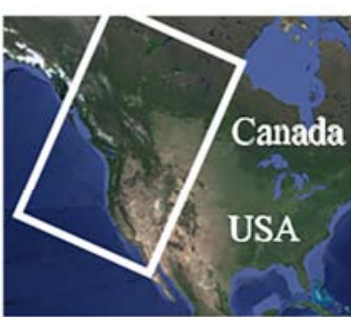

Geometrical map
Figure 5. Color composite image consisting of GCOM-C/SGLI measurements over North West Coast around Canada-United State border on September 18, 2020 is shown on the left side. For reference, the geometrical map, cited from Google, is on the right side, with the white rectangle approximately corresponding to the satellite image on the left.

Figure 6 presents the distribution of AAI and DDI over the same area as the image on the left in Figure 5, and each histogram within the white rectangle on each upper image. Figure 6 indicates that the heavy smoke area coincided with the area with high $\mathrm{AAI} \geq 0.83$ and low $\mathrm{DDI} \leq 1.1$ as denoted by the dashed arrow lines with numerical values. These values coincide with the aerosol type classification charts shown in 
Figure 4 derived in the previous subsection. From this, it can be stated that the proposed algorithms for aerosol type classification have been validated by the smoke scene presented in Figure 5, which illustrated that our discrimination chart is effective for BBA type aerosols.
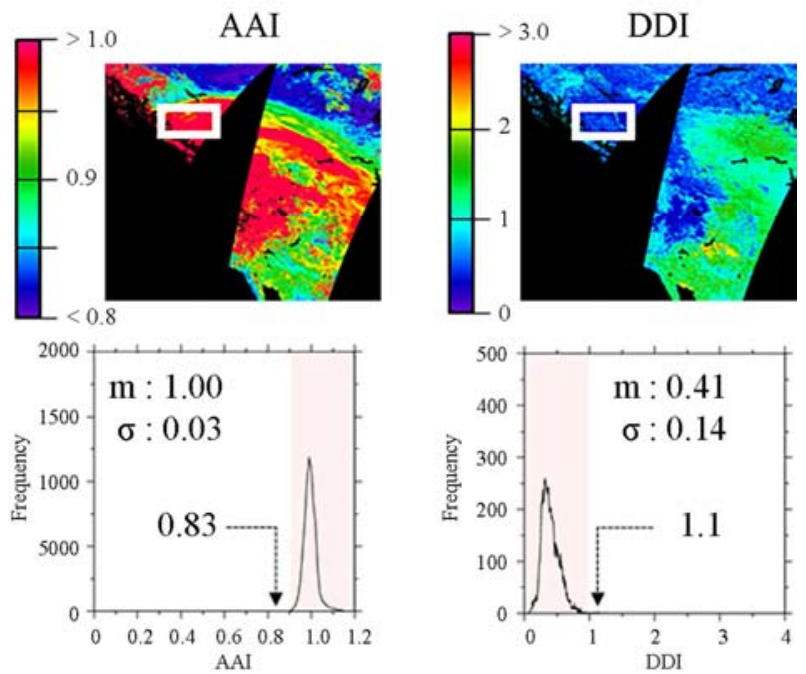

Figure 6. Distribution map and histogram for all detection items for BBA in the same scenario shown in the left in Figure 4. Note that histograms are distributed within the white frame rectangle in each image. The values were derived from GCOM-C/SGLI/L2 measurements on September 18, 2020.

The verification was only one application of our algorithm for aerosol type classification based on SGLI products to the region where the aerosol type was known as a biomass burning aerosol (BBA) due to the forest fire. The sensitivity test of the separation technique should be carried out over regions where neither of these aerosol types are likely to be present. The AOT values provided by ground measurements of NASA/AERONET are examined in comparison to AAI and/or DDI by SGLI. It is noted that GCOM-C/SGLI takes approximately two days for the entire coverage of the Earth and has a four-day recurrence period in the mid-latitude region. The SGLI therefore, has a limited number of encounters with a certain AERONET site during the two years from 2018 to 2019 . Although the total amount of data is inadequate for statistical processing of the relationship between SGLI data and the values of AOT at some AERONET sites, its correlation can be used for verification of BBA and DUST distinction chart presented in Figure 4.

Figure 7 presents SGLI/AAI and DDI dependency on the NASA/AOT $(0.50 \mu \mathrm{m})$ and the cumulative frequency at selected AERONET sites shown in the top map (refer to https://aeronet.gsfc.nasa.gov/). The upper and lower groups in Figure 7 correspond to BBA and DUST, respectively. The values of AOT were provided from AERONET-V3-L1.5. The measurements were selected at the AERONET sites of Alta_Floresta, CUIABA-MIRANDA, Itajuba, Ji_Parana_SE, Rio_Branco, SANTA_CRUZ_UTEPSA, and Sao_Paulo in the Amazon region, Bujumbura in South Africa, and Irkutsk and Yakutsk in Siberia from July 1 to Oct. 31 in 2018 and 2019 for BBA denoted by red circles in AERONET site map.
DUST measurements at the Tamanrasset site in the Sahara (circles by dark yellow) were selected from May 1, 2018 to Dec. 31, 2019. The time difference between both measurements of AERONET/AOT and SGLI is within \pm 15 min. At a glance the validation in a case of BBA seems to be limited to thick AOT. Therefore the cumulative frequency graph was presented only the case of AOT $\geq 1.0$. However, comparing the behavior of AAI and DDI with respect to AOT in the case of BBA presented in Figures 2 and 3 with that in Figure 7 , there is no contradiction between the two. It is possible to mention that our discrimination chart of Figure 4 is effective for AERONET measurements.
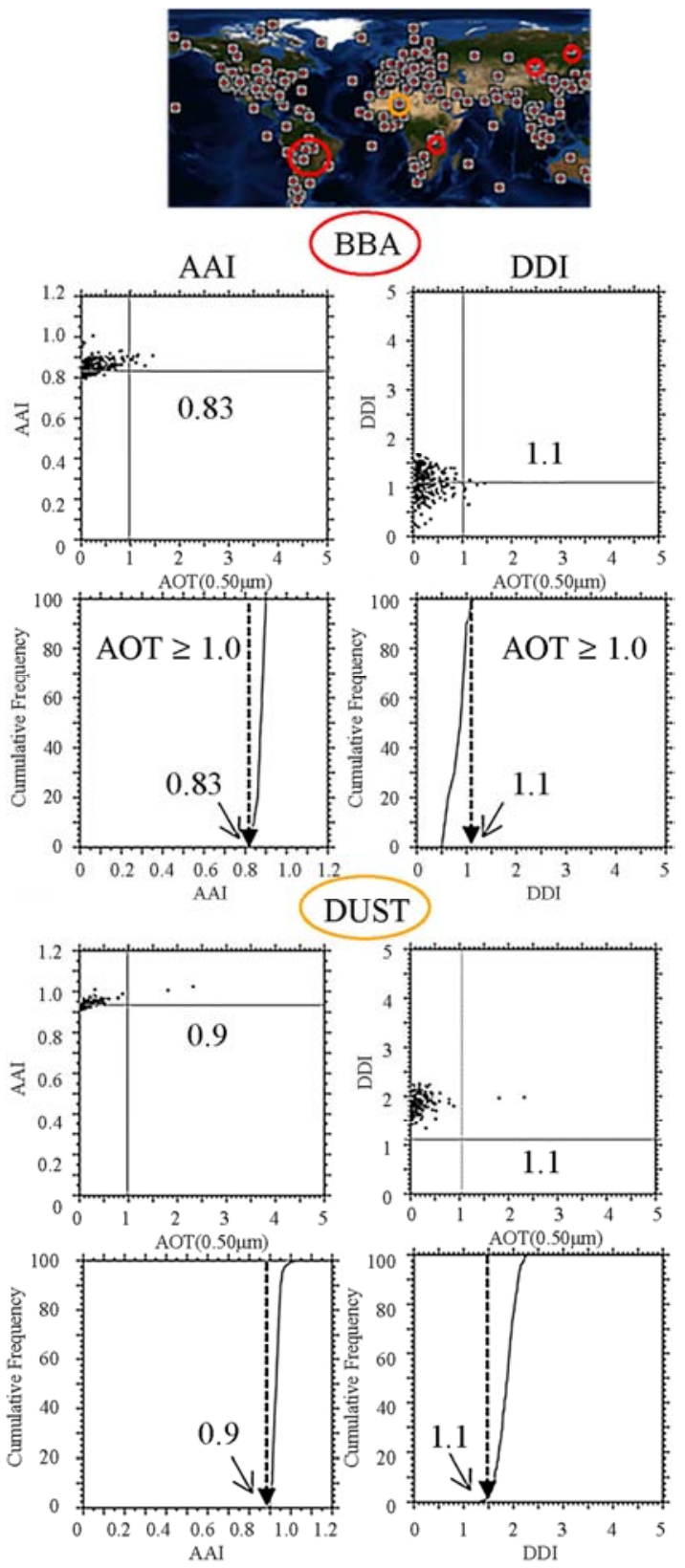

Figure 7. Evaluation of $A A I$ and DDI by SGLI versus AOT by NASA/AERONET. The top map denotes the geographical position of AERONET sites (https://aeronet.gsfc.nasa.gov/). The upper and lower groups correspond to BBA and DUST, respectively. The upper and lower in each group represent dependency of $A A I$ and DDI on the AOT $(0.5 \mu \mathrm{m})$ and accumulated frequency, respectively. 


\section{Detection of Aerosols Above Clouds}

\subsection{Detection of Clouds}

The difficulty pertaining to detecting clouds in terms of our AAI and DDI is challenged. The AAI and DDI values were examined for water and ice cloud flag pixels in Figure 8, where the cloud flag and cloud optical thickness (COT $(0.50 \mu \mathrm{m}))$ were derived from SGLI/Level-2 products from May 1, 2018 to August 23, 2019.
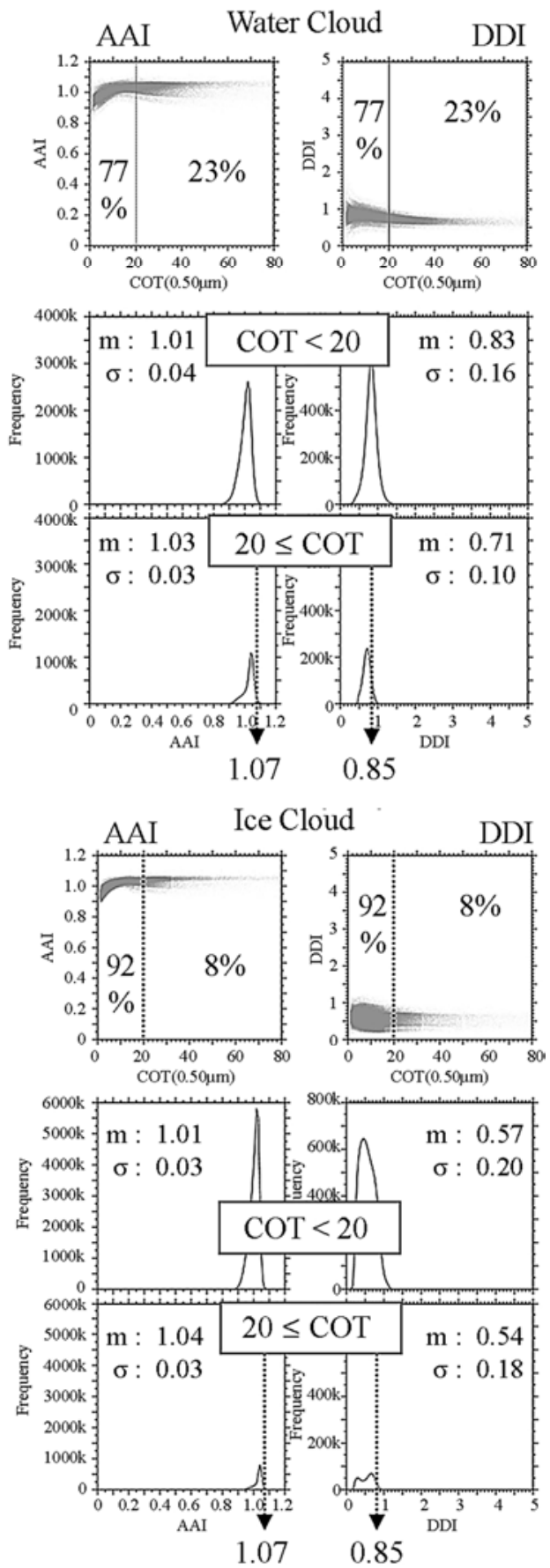

Figure 8. AAI and DDI from SGLI/Level-2 cloud flag pixels from May 1, 2018 to August 23, 2019 for water cloud and ice cloud in the upper and lower groups, respectively. The top histogram is the AAI and DDI vs COT(0.5) from $S G L I / L e v e l-2$, and the middle and bottom histograms represent the domain of $\operatorname{COT}(0.5)$ at $[0,20]$ and $\operatorname{COT}(0.5) \geq 20$, respectively, in each group.
The COT behavior was rather different between the water and ice clouds. Usually, each ice cloud item converged faster with the COT than that of the water clouds. Additionally, mixed regions of clouds and aerosols are frequently found in SGLI/Level-2 products. To further explore this issue, the clouds need to be handled more precisely. The structure and physics of clouds are complicated, hence, it is impossible to detect them, especially optically thin cirrus clouds. Although much research on cloud detection has already been done, we will also tackle this issue next. When the fine feature of clouds is ignored, color indices for the AAI and DDI for clouds showed stable behavior in the region with a COT $(0.50 \mu \mathrm{m}) \geq 20$. The pixels with $\operatorname{COT}(0.5) \geq 20$ of water cloud approximately correspond to $23 \%$ and those of ice clouds to $8 \%$ as represented at top figure in each group of Figure 8. In other words, the optical thickness of the ice cloud is usually less than that of the water cloud. The thick water clouds at $\operatorname{COT}(0.5) \geq 20$ are sufficient to cover the underlying aerosols or the Earth's surface. Roughly speaking, the values of AAI approach 1.07 and the acquired values of DDI are less than 0.85 for optically thick clouds.

In comparison of the results in Figure 8 with the aerosol classification in Figure 4, the AAI is not available for the distinction of thick clouds from absorbing aerosols. The DDI for DUST is evidently higher than that of the thick cloud. This fact suggests that DUST above the clouds is detectable using DDI. Some practical examples based on SGLI measurements are examined to evaluate upcoming issues such as the detection of aerosols over clouds.

\subsection{Dust Above Water Clouds}

In this section, interesting examples of DUST aerosols above clouds are presented. As interpreted in the previous subsection, DUST aerosols took values of the index DDI $\geq 1.1$ at every interval of AOT (refer to Figure 3). On the other hand, the index DDI $\leq 0.85$ for thick clouds (refer to Figure 8). These results suggest that DUST above clouds is detectable using DDI. It is a really pity to know from Figures 2, 4 and 8 that the index AAI is not useful to detect absorbing aerosols over clouds as already mentioned above. Then, pixels with DDI values higher than 1.1 existing above the water cloud seem to be candidates for DUST particles above clouds.

Figure 9 presents the SGLI measurements over the ocean in the southeast front area of the Arabia peninsula observed on August 2, 2018. Figure 9a denotes the geometrical map, Figures $9 \mathrm{~b}$ and $\mathrm{c}$ represent the distribution of the COT (0.5) of water clouds and DDI within the white frame rectangle in the Figure 9a map, respectively. It is clear that DDI higher than 1.1 pixels exists above the water cloud. The thick cloud obviously takes low DDI values less than 0.85 (see Figure 8). It has been drawn from Figures 3 and 4 that the pixels with DDI $\geq 1.1$ are definitely DUST. That is, Figure $9 \mathrm{c}$ is the scene of DUST aerosols above thick water clouds. The DUST particles probably come from Rub Al Khali Desert on the Arabia peninsula. 
(a)

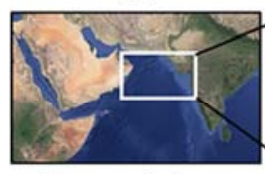

Geometrical map (b)

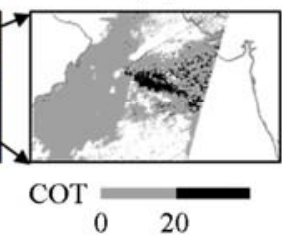

(c)

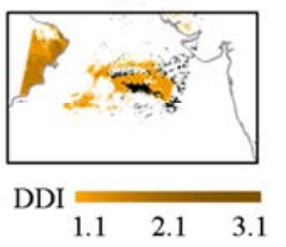

Figure 9. Images over the ocean in the southeast front area of the Arabian Peninsula, Figures $a, b$, c present geometrical map, water cloud and DDI distributions observed by SGLI on August 2, 2018, respectively.

The fact suggested by Figure 9 as DUST advection from the desert on the Arabia peninsula is demonstrated in Figure 10 referred from NASA/World View (https://worldview.earthdata.nasa.gov) based on Terra/MODIS [43]. In Figure 10, the upper five figures represent color composite images and the ones at the bottom represent COT distribution superposed on each color image. It is found from Figure 10 that the sand storm advection was clearly arranged in time series from Rub Al Khali desert on the Arabian Peninsula on July 29 over the Arabian Sea to the southeastern front area of the peninsula on August 2, 2018. The satellite transit times from Terra and GCOM-C are slightly different from each other. The cloud movements observed by both satellites do not necessarily match though, it should be noted that Figure 9c suggests an interesting scene of DUST above water clouds. Although the analysis of this complicated case is a future issue, the detection of Dust aerosols above clouds using DDI only is quite interesting.

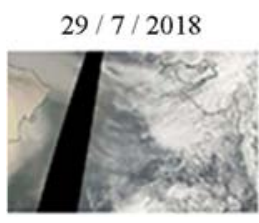

$31 / 7 / 2018$
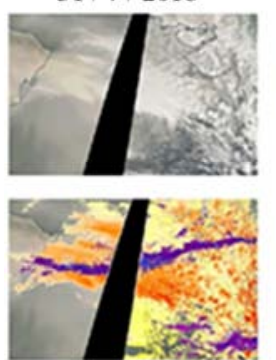

$30 / 7 / 2018$

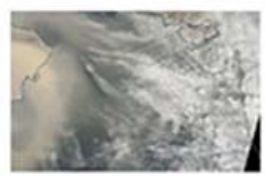

$1 / 8 / 2018$
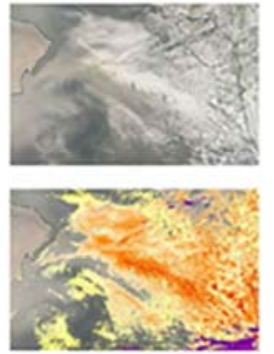

$2 / 8 / 2018$
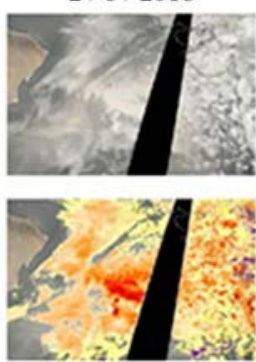

Figure 10. NASA/World View (https://worldview.earthdata.nasa.gov) based on Terra/MODIS. The upper five figures present color composite images from July 29, 2018 to August 2, 2018, the lower three represent COT superposed on each color image from July 31 to August 2, 2018.

Some other cases for the detection of DUST above water clouds are introduced in Figure 11. These figures are the same as Figures 9 and 10 but for other areas on other days as follows:

1. Eastern area of Gobi Desert (namely inner Mongolia) on May 16, 2019,

2. Taklimakan Desert on May 19, 2019,

3. Western coast of Sahara Desert on August 26, 2019.

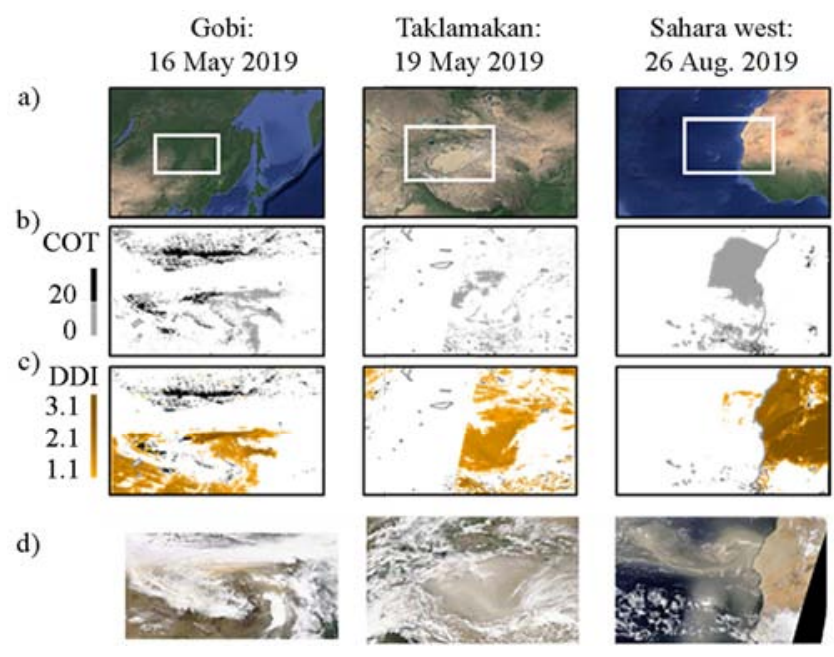

Figure 11. Similar to Figures 9 and 10 but for Gobi Desert on May 16, 2019, Taklimakan Desert on May 19, 2019, and West coast of Sahara Desert on August 26, 2019 in the left, middle and right columns, respectively. Figures 11 $a, b, c$ and $d$ represent geometrical maps, COTs of water cloud and DDIs derived from SGLI and color composite images superposed on each color image referred from $N A S A /$ World View based on Terra/MODIS, respectively.

\subsection{BBA Above Water Clouds}

The aerosols above clouds are not necessarily Dust types. BBA or other type aerosols or mixture of various type aerosols is considerable. The index DDI alone is powerless to deal with these difficult issues. Unfortunately, the index AAI cannot be used. At any rate, we have to devise another tools for challenge of an inevitable task as detection of BBA above water clouds. Hence, polarization information is examined. The SGLI has two polarization channels with fine resolution of $1 \mathrm{~km}$ in the red $(0.67 \mu \mathrm{m})$ and near-IR $(0.86 \mu \mathrm{m})$ wavelengths (strictly speaking, $0.6735 \mu \mathrm{m}$ and $0.8685 \mu \mathrm{m}$, refer to Figure 1). Observing the target together with radiance and polarization is essential. This is the advantage of SGLI. Here, we take this advantage with respect to detection of BBA type aerosols above clouds. The polarized radiance $(\operatorname{Pol}(\lambda))$ at a wavelength $\lambda$ is defined with Stokes parameters $(I, Q, U, V)$ as follows:

$$
\operatorname{Pol}(\lambda)=\sqrt{Q^{2}+U^{2}}
$$

A plus or minus sign of $\operatorname{Pol}(\lambda)$ follows $Q$. The degree of polarization (Pol. Deg. $(\lambda)$ ) is defined as

$$
\text { Pol. Deg. }(\lambda)=\operatorname{Pol}(\lambda) / I(\lambda) \text {. }
$$

Figure 12 represents the cumulative frequency and the averaged value $(\mathrm{m})$ and the standard deviation $(\sigma)$ for each case, namely Figures 12a, b and c present BBA, DUST and water clouds, respectively. It is clear from Figure 12 that Pol. Deg. (0.67) in the case of BBA is higher than $10 \%$, but DUST and optically thick water clouds take the values of Pol. Deg. (0.67) less than 10\%. This fact suggests Pol. Deg. (0.67) is an indicator to detect BBA above water clouds. 
Cumulative frequency of Pol. Deg. (0.67)

$\begin{array}{lll}\text { (a) BBA } & \text { (b) DUST }\end{array}$

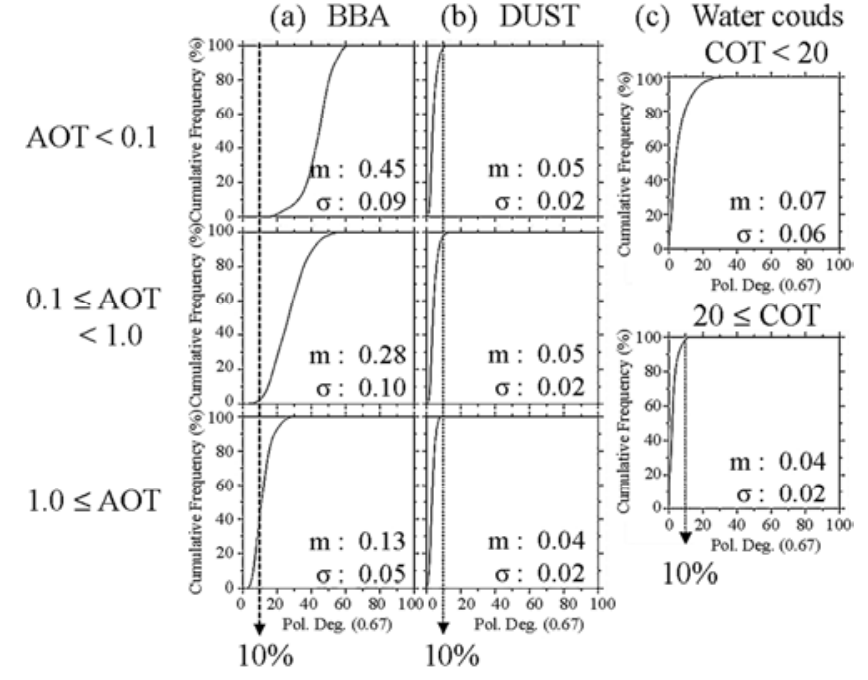

Figure 12. Cumulative frequency (\%) of degree of polarization at a wavelength of $0.67 \mu m$ (Pol. Deg.(0.67)). Figures $12 a, b$ and $c$ represent the case of BBA, DUST and water clouds, respectively. The values of $m$ and $\sigma$ denote mean value and standard deviation, respectively, derived from the histogram of pixel numbers in each case.

Figure 13 presents the satellite images over the southeastern South America on 1, 2 and 3 August in 2019. Figures a, b, c and $\mathrm{d}$ represent geometrical maps, COTs of water cloud and Pol. Deg. (0.67) derived from SGLI, and color composite image referred from NASA/World View based on Terra/MODIS, respectively. It can be said Figure 13 illustrates the interesting phenomenon of BBA above water clouds. Biomass burning plumes have often happened in this area of the southeastern South America particularly in August and September [44].

\section{Southeastern South America}

(a)
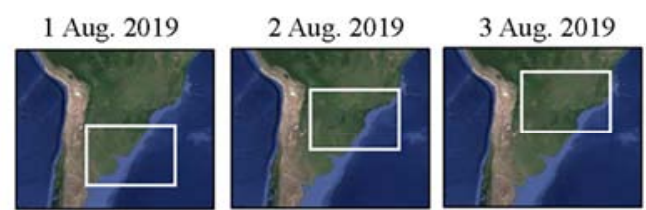

(b)
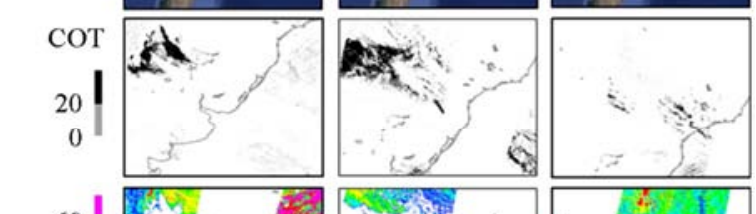

(c)

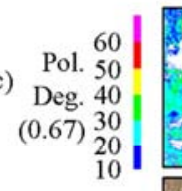

(d)
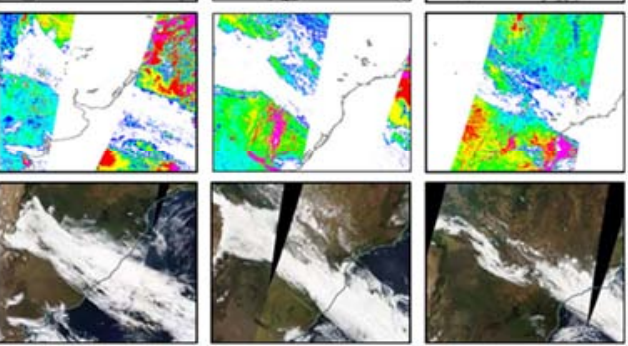

Figure 13. The same as Figure 11 but for BBA above clouds over southeastern South America on 1, 2 and 3 in August in 2019. Figures 12a, b, c and d represent geometrical maps, COTs of water cloud and Pol. Deg. (0.67) derived from SGLI, and color composite image referred from NASA/World View based on Terra/MODIS, respectively.
Further considerations were required regarding the effective utilization of polarization information limited to detection of BBA above water clouds. Simple questions of whether polarized radiance, its color ratio or polarization degree are suitable for this issue were considered more carefully. Note that SGLI polarization measurements are restricted to one directional observation not multi-directional one like POLDER. Anyway it is of interesting that the detection of BBA aerosols above water clouds using polarization degree at a wavelength $0.67 \mu \mathrm{m}$ only has made.

\subsection{Case Studies of Global Distribution of Aerosols by Type}

It is self-evident that several kinds of aerosols exist above ice or water clouds of various optical thickness in nature. In the previous subsections, detection of aerosols above clouds (AAC) were quantitatively dealt with just for the case of BBA type aerosol or DUST one above optically thick $(\operatorname{COT}(0.5) \geq 20)$ water clouds over land. In that sense, such an issue as effective detection of AAC in general has been left and should be continued working for comprehension the impacts of aerosols upon clouds and/or climate. However, practical examples of global distribution of the limited aerosol types as BBA or DUST above water cloud provide us with some suggestions regarding the advection of aerosols and an indicator of the lower limit of the direct AAC radiative forcing in the global radiation budget [27].

As examples, Figure 14 presents the global distribution of atmospheric composition, namely aerosols by type discriminated in Figure 4, clouds from SGLI/L2 products, and DUST or BBA aerosols above optically thick $(\operatorname{COT}(0.5) \geq 20)$ water clouds detected according to the procedure described in subsection 3.2 or 3.3 , respectively, over land. The coloring of aerosol type is the same as Figure 4 , and the optically thick water cloud $(\operatorname{COT}(0.5) \geq 20)$ is denoted by dark gray and other clouds in light gray in Figure 14. The table under the global map shows the percentage of pixels of each atmospheric composition within \pm 60 degrees latitude over land measured by SGLI. Naturally, the value depends on the observation date, but it can be roughly said that $60 \%$ or more are clear sky and $40 \%$ or less are covered by clouds including $3 \%$ or less optically thick $(\operatorname{COT}(0.5) \geq 20)$ water clouds. From the results in Figure 14, it's clear to see that our assumptions as thick water clouds are too limited to deal with the aerosols above clouds. That's why Dust above cloud case is very few. The lower left figures in each map present an enlarged figure corresponding to the small black frame square in the global map and its color composite image for a demonstration of AAC. An example of top figure presents Dust aerosols above clouds, and middle and bottom demonstrate examples present the cases of BBA above clouds. Throughout three maps, it's the season when wildfire occurred and lots of DUST particles were seen within the so called dust belt $\left(5-40^{\circ} \mathrm{N}\right)$. 

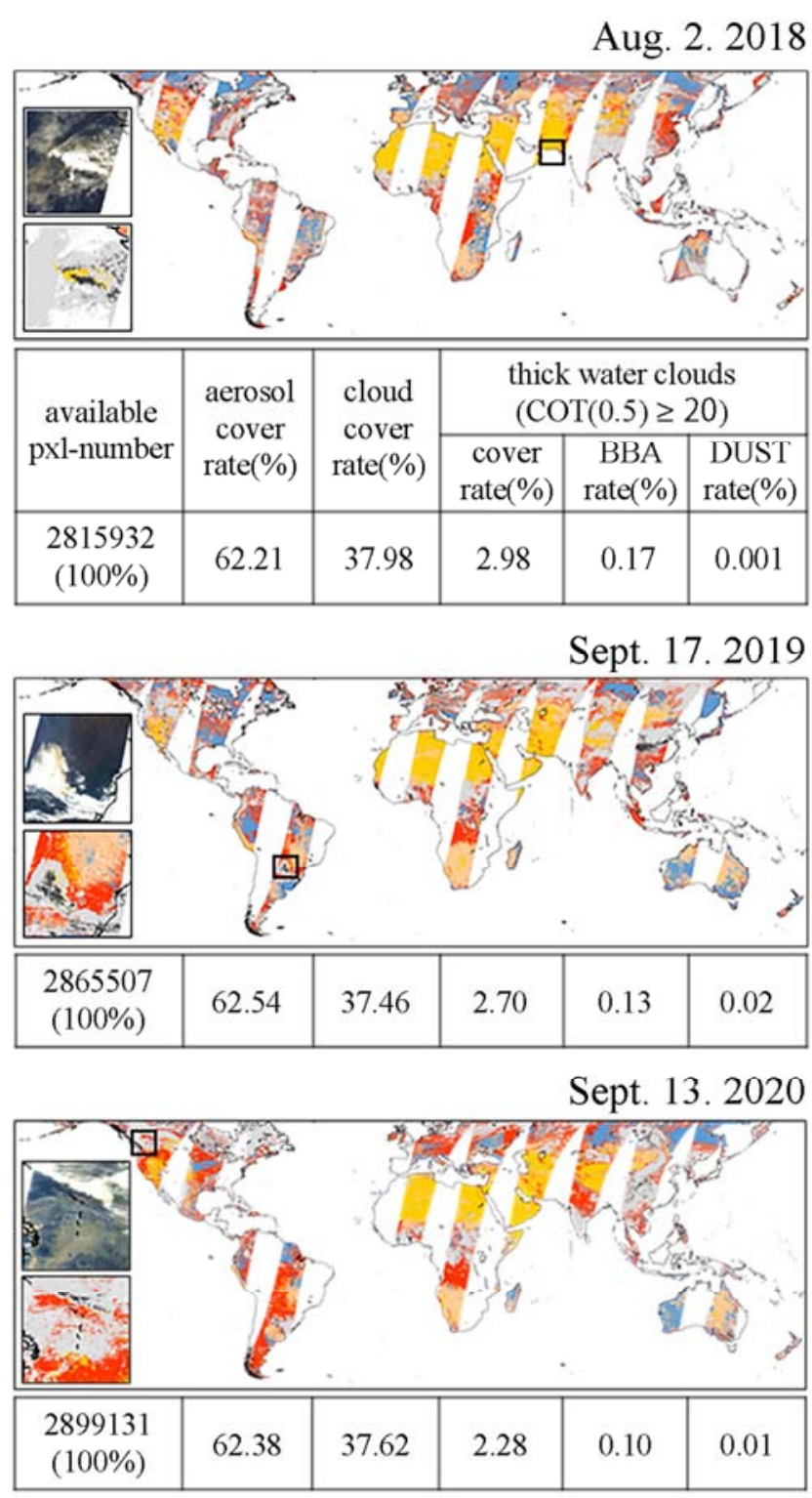

Figure 14. Global distribution of atmospheric composition. The coloring of aerosol type is the same as Figure 4, and the optically thick water cloud $(C O T(0.5) \geq 20)$ is denoted by dark gray and other clouds in light gray.

Recently, the combination of active and passive satellite sensor [45] or high- temporal- resolution by geostationary satellite [46] have provided useful products on aerosols above clouds. We will also continue to challenge this issue based on utilization SGLI polarization information and combination with other satellite data.

\section{Summary}

In this work, the aerosol type classification algorithms proposed in the previous work [1] were applied to a recent Japanese mission GCOM-C/SGLI. The advantages of near-UV data at $0.38 \mu \mathrm{m}$ and $0.41 \mu \mathrm{m}$ wavelength channels collected using the ADEOS-2/GLI launched in 2002 were examined alongside those of GCOM-C/SGLI in 2017. The absorbing aerosol index; AAI=R (0.41) / R (0.38) defined in Eq. (1); for the detection of absorbing aerosols as BBA or DUST, as well as the dust detection index; DDI $=\mathrm{R}(1.63) / \mathrm{R}(0.38)$ in Eq. (2): for discriminating BBA from DUST were practically applied for SGLI measurements. Several procedures have been proposed to detect absorbing aerosols. Comparatively, our AAI and DDI took a simple form that says only the ratio of two-channel satellite data, which made their application to any other satellite data easier. The discrimination chart for aerosol types created based on results obtained after processing a sufficient number of SGLI measurements was presented in Figure 4, and practically verified in the case of a large forest fire in North West Coast around Canada-United State border that happened on September 18, 2020. From the verification results, the correctness of chart was proved.

Moreover, the detection of optically thick clouds was evaluated using similar algorithms. It was found that much more spectral information was required for efficient detection/separation of water/ice clouds. On the other hand, fortunately DDI index, and Pol. Deg. (0.67) were available to detect DUST, or BBA type aerosols above optically thick water clouds, respectively. Further considerations were required regarding the detection of unlimited aerosols above clouds. That is an inevitable next subjects along with aerosol retrieval in the combined system of aerosol above cloud.

The classification of aerosol types is available because an understanding of aerosol types facilitates subsequent aerosol retrieval denoted. Present scheme of aerosol type distinction is limited to the intrinsic BBA or DUST alone, against the facts. In this work, we have classified sulfate-based aerosols or all mixed cases as "others", but in reality the "others" category is the most common. In the case of aerosol retrieval, finding the BBA/DUST helps the subsequent retrieval of size or refractive index of the surrounding BBA/DUST like aerosols by slightly changing the properties of the BBA/DUST. This process is very efficient for all aerosol retrieval. These findings demonstrate that the present work is available for aerosol retrieval in severe aerosol events using vector radiation simulations [47, 48]. This study further emphasizes the importance of rapid detection of severe aerosol events [49].

This work, using a sufficient number of new real GCOM-C/SGLI data will be available for other future missions. Further studies should consider the following:

1. Comparison and combination with multi-satellite data.

2. Effective cloud detection.

3. Detection of aerosols above clouds in general.

4. Characterization of aerosols/clouds in the combination system of aerosol above cloud.

\section{Acknowledgements}

The authors would like to thank JAXA for distributing GCOM-C/SGLI data and NASA for offering World View information. This work was supported in part by the Global Change Observation Mission - Climate project by JAXA (no. JX - PSPC - 524344), JSPS KAKENHI Grant Number 19h04242 and the Beyond Europe project (GRASP-cloud) by FFG (Austria). 


\section{References}

[1] Mukai, S., Sano, I. and Nakata, M. (2019). Algorithms for the classification and characterization of aerosols: Utility verification of near-UV satellite observations, J. Appl. Rem. Sen. 13 (1), 014527, doi: 10.1117/1.JARS.13.014527.

[2] Twomey, S. (1974). Pollution and planetary albedo, Atmos. Environ., 25, 2435-2442.

[3] Albrecht, B.(1989). Aerosols, cloud microphysics, and fractional cloudiness," Science, 245, 1227-1230, doi: 10.1126/science.245.4923.1227.

[4] Takemura, T., Kaufman, Y. J., Remer, L. A., and Nakajima, T. (2007). Two competing pathway of aerosol effects on cloud and precipitation formation, Geophys. Res. Let., 34, L04802, doi: 10.1029/2006GL028349.

[5] Mukai, M., Nakajima, T. and Takemura, T. (2008). Anthropogenic impacts on the radiation budget and the cloud field in East Asia based on model simulations with GCM, J. Geophys. Res., 113, D12211, doi: 10.1029/2007JD009325.

[6] Takahashi, H. G., Watanabe, S., Nakata, M., and Takemura, T. (2018). Response of the atmospheric hydrological cycle over the tropical Asian monsoon regions to anthropogenic aerosols and its seasonality, Progress in Earth and Planetary Science, 5 (44).

[7] Sokolik, I. and Toon, O. (2018). Direct radiative forcing by anthropogenic airborne aerosols, Nature, 381, 681-683, doi: 10.1038/381681a0.

[8] Liao, H. and J. Seinfeld, J. (1998). Effect of clouds on direct aerosol radiative forcing of climate, J. Geophys. Res., 103, D103, 3781-3788, doi: 10.1029/97JD03455.

[9] Jacobson, M. (2001). Strong radiative heating due to the mixing state of black carbon in atmospheric aerosols, Nature. 409, 696-697, doi: 10.10381/35055518.

[10] IPCC (2013). Climate Change 2013: The Physical Science Basis. Contribution of Working Group I to the Fifth Assessment Report of the Intergovernmental Panel on Climate Change, Cambridge University Press, 1535 pp., ISBN 978-1-107-05799-1.

[11] Kirchstetter, T. and T. Novakov, T. (2004). Evidence that the spectral dependence of light absorption by aerosols is affected by organic carbon, J. Geophys. Res., 109, D21208, doi: 10.1029/2004JD004999.

[12] Kalashnikova, O., Garay, M., Bates, Chen, Y. and Bond, T. C. (2010). Light absorption by organic carbon from wood combustion, Atmos. Chem. Phys., 10, 1773-1787, doi: 10.5194/acp-10-1773-2010.

[13] Kalashnikova, O., Garay, M., Bates, K., Kenseth, C., Kong. W., Cappa, C., Lyapustin, A., Jonsson, H., Seidel, F., Xu, F., Diner, D. and Seinfeld, J. (2018). Photopolarimetric sensitivity to black carbon content of wildfire smoke: results from the 2016 ImPACT-PM field campaign, J. Geophys. Res., 123, 5376-5396, doi: 10.1029/2017JD028032.

[14] Fernandez, R. (2002). Do humans create deserts?, Trends Ecol. Evol., 17, 6-7, doi: 10.1016/S0169-5347(01)02366-7.
[15] Wagner, R., Ajtai, T., Kandler, K., Lieke, K., Linke, C., Müller, T., Schnaiter, M. and Vragel, M. (2012). Complex refractive indices of Saharan dust samples at visible and near UV wavelengths: a laboratory study, Atmos. Chem. Phys., 12, 2491-2512, doi: 10.5194/acp-12-2491-2012.

[16] Di Biagio, C., Formenti, P., Balkanski, Y., Caponi, L., Cazaunau, M., Pangui, E., Journet, E., Nowak, S., Caquineau, S., Andreae, M., Kandler, K., Saeed, T., Piketh, S., Seibert, D., Williams, E. and Doussin, J. (2017). Global scale variability of the mineral dust long-wave refractive index: a new dataset of in situ measurements for climate modeling and remote sensing, Atmos. Chem. Phys., 17, 1901-1929, doi: 10.5194/acp-17-1901-2017.

[17] Littmann, T. (1991). Dust storm frequency in Asia: Climatic control and variability, International Journal of Climatology, $11,393-412$.

[18] Kinne, S., Lohmann, U., Feichter, J., Schulz, M., Timmreck, C., Ghan, S., Easter, R., Chin, M., Ginoux, P., Takemura, T., Tegen, I., Koch, D., Herzog, M., Penner, J., Pitari, G., Holben, B., Eck, T., Smirnov, A., Dubovik, O., Slutsker, I., Tanre, D., Torres, O., Mishchenko, M., Geogdzhayev, G., Chu, D. and Kaufman, Y. (2003). Monthly averages of aerosol properties: A global comparison among models, satellite data and AERONET ground data, J. Geophys. Res., 108, D20, 4634, doi: 10.1029/ 2001JD 001253.

[19] Westervelt, D., W. Horowitz, L., Naik, V., Golaz, J. and Mauzerall, L. (2015). Radiative forcing and climate response to projected $21^{\text {st }}$ century aerosol decreases, Atmos. Chem. Phys., 15, 12681-12703, doi: 10.5194/acp-15-12681-2015.

[20] Jung, J., Souri, A., Wong, D., Lee, S., Jeon, W., Kim, J. and Choi, Y. (2019). The impact of the direct effect of aerosols on meteorology and air quality using aerosol optical depth assimilation during the KORUS-AQ campaign, J. Geophys. Res., 124, (14), doi: 10.1029/2019JD030641.

[21] King, M., Menzel, P. Kaufman, Y., Tanré, D., Gao, B., Platnick, S., Ackerman, S., Remer, L. Oincus, R. and Hubanks, P. (2003). Cloud and aerosol properties, precipitable water, and profiles of temperature and water vapor from MODIS, IEEE Trans. Geosci. Remote Sens., 41 (2), 442-458, doi: 10.1109/TGRS.2002.808226.

[22] Remer, L., Levy, R., Mattoo, S., Tanré, D., Gupta, P., Shi, Y., Sawyer, V., Leigh A. Munchak' L., Zhou, Y., Kim, M., Ichoku, C., Patadia, F., Li, R., Gassó, S., Kleidman, R. and Holben, B. (2020). The Dark Target Algorithm for Observing the Global Aerosol System: Past, Present, and Future, Remote Sens., 12 (18), 2900; doi.org/10.3390/rs12182900.

[23] Torres, O., Bhartia, P., Herman, J., Ahmad, J. and Gleason, J. (1998). Derivation of aerosol properties from satellite measurements of backscattered ultraviolet radiation: Theoretical basis, J. Geophys. Res., 103, 17099-17110, doi: 10.1029/98JD00900.

[24] Torres, O., (2007). Aerosols and surface UV products from OMI observations: An overview, J. Geophys. Res., 112 (D24S47), doi: 10.1029/2007/JD008809.

[25] Deuzé, J., BréOn, F., Devaux, C., Goloub, P., Herman, M., Lafrance, B., Maignan, F., Marchand, A., Nadal, F., Perry, G., and Tanré, D. (2001). Remote sensing of aerosols over land surfaces from POLDER/ADEOS-1 polarized measurements, J. Geophys. Res., 106, 4913-4926, doi: 10.1029/2000JD900364. 
[26] Waquet, F., Cornet, C., Deuzé, J., Dubovik, O., Ducos, F., Goloub, P., Herman, M., Lapyonok, T., Labonnote, L., Riedi, J., Tanré, D., Thieuleux, F. and Vanbauce, C. (2013). Retrieval of aerosol microphysical and optical properties above liquid clouds from POLDER/PARASOL polarization measurements," Atmos. Meas. Tech., 6, 991-1016, doi: 10.5194/amt-6-991-2013.

[27] Waquet, F., Peers, F., Ducos, F., Goloub, P., Platnick, S., Riedi, J., Tanré, D., and Thieuleux, F. (2013). Global analysis of aerosol properties above clouds, Geophys. Res. Lett., 40, 5809-5814, https://doi.org/10.1002/2013GL057482.

[28] Peers, F., Waquet, F., Cornet, C., Dubuisson, P., Ducos, F., Goloub, P., Szczap, F., Tanré, D. and Thieuleux, F. (2015). Absorption of aerosols above clouds from POLDER/PARASOL measurements and estimation of their direct radiative effect, Atmos. Chem. Phys., 15, 4170-4196, doi: 10.5194/acp-15-4179-2015.

[29] Eck, T., Holben, B., Reid, J., Dubovik, O., Smirnov, A., O'Neill, N., Slutsker, I. and Kinne, S.(1999). Wavelength dependence of the optical depth of biomass burning, urban, and desert dust aerosols, J. Geophys. Res., 104 (D24), 31333-31349, doi: 10.1029/1999JD900923.

[30] O'Neill, N., Dubovik. O. and Eck, T., "Modified Angstrom exponent for the characterization of submicrometer aerosols," Applied Optics, 40, 2368-2375, doi: /10.1364/AO.40.002368 (2001).

[31] Dubovik, O., Holben, B., Eck, T., Smirnov, A., Kaufman, Y., King, M., Tanré, D. and Slutsker, I. (2002). Variability of absorption and optical properties of key aerosol types observed in worldwide locations, J. Atmos. Sci., 59, 590-608, doi: 10.1175/1520-0469.

[32] Omar, A., Won, J., Winker, D., Yoon, S., Dubovik, O., and McCormick, P. (2005). Development of global aerosol models using cluster analysis of Aerosol Robotic Network (AERONET) measurements, J. Geophys. Res. 110 (D10S14), 1-14, doi: 10.1029/2004JD004874.

[33] Omar, A., Winker, D., Vaughan, M., Hu, Y., Trepte, C., Ferrare, R., Lee, K., Hostetler, C., Kittaka, C., Rogres, R., Kuehn, R. and Liu, Z. (2009). The CALIPSO Automated Aerosol Classification and Lidar Ratio Selection Algorithm, J. Atmos. Ocean. Tech., 26, 1994-2014, doi: 10.1175/2009JTECHA1231.1.

[34] Burton, S., Ferrare, R., Hostetler, C., Hair, J., Rogers, R., Obland, M., Butler, C., Cook, A., Harper, D. and Froyd, K. (2012). Aerosol classification using airborne High Spectral Resolution Lidar measurements - methodology and examples, Atmos. Meas. Tech., 5, 73-98, doi: 10.5194/amt-5-73-2012.

[35] Hamill, P., Giordano, M., Ward, C., Giles, D. and Holben, B. (2016). An AERONET-based aerosol classification using the Mahalanobis distance, Atmos. Environ., 140, 213-233, doi: 10.1016/j.atmosenv.2016.06.002.

[36] Hsu, N., Herman, J., Bhartia, P., Seftor, C., Torres, O., Thompson, A., Gleason, J., Eck, T. and Holben, B. (1996). Detection of biomass burning smoke from TOMS measurements, Geophys. Res. Lett., 23, 745-748, doi: 10.1029/96GL00455.

[37] Chiapello, I., Prospero, J., Herman, J. and Hsu, N. (1999). Detection of mineral dust over the North Atlantic Ocean and
Africa with the Nimbus 7 TOMS, J. Geophys. Res., 104, 9277-9291, doi: 10.1029/1998JD200083.

[38] Sano, I., Mukai, S., Okada, Y. and Mukai, M. (2009). Retrieval algorithm based on combined use of POLDER and GLI data for biomass aerosols, J. Rem. Sens. Soc. Jpn., 29 (1), 54-59, doi: 10.11440/rssj.2954.

[39] de Graaf, M., Stammes, P., Torres, O. and Koelemeijer, R. (2005). Absorbing Aerosol Index: Sensitivity Analysis, application to GOME and comparison with TOMS, $J$. Geophys. Res., 102 (D14), 16,911-16,921, doi: 10.1029/2004JD005178.

[40] Ciren, P. and S. Kondragunta, S. (2014). Dust aerosol index (DAI) algorithm for MODIS, J. Geophys. Res., 119, 4770-4792, doi: 10.1002/2013JD020855.

[41] Lensky, I. and Rosenfeld, D. (2008). Clouds-Aerosols-Precipitation Satellite Analysis Tool (CAPSAT)," Atmos. Chem. Phys., 8, 6739-6753, doi: 10.5194/acp-8-6739-2008 (2008).

[42] Mukai, S., Sano, I. and Nakata, M. (2019). Inheritance of aerosol retrieval by GCOM-C/SGLI from ADEOS-2/GLI, Proc. SPIE 11152, Remote Sensing of Clouds and the Atmosphere XXIV, 1115215; doi: 10.1117/12.2532504.

[43] Jethva, H, Torres, O., Remer, L., Redemann, J., Livingston, J., Dunagan, S., Shinozuka, Y., Kacenelenbogen, M., Rosenheimer, M., and Spurr, R. (2016). Validating MODIS above-cloud aerosol optical depth retrieval from "color ratio" algorithm using direct measurements made by NASA's airborne AATS and 4STAR sensors, Atmos. Meas. Tech., 9, 5053-5062, doi: 10.5194/amt-9-5053-2016.

[44] Mukai, S., Yokomae, T., Sano, I. and Nakata, M. (2012). Multiple scattering in a dense aerosol atmosphere, Atmos. Mes. Tech. Discuss, 5, 881-907, doi: 10.5194/amtd-5-881-2012.

[45] Lucia D., Waquet, F., Josset, D., Ferlay, N., Peers, F., Thieuleux, F., Ducos, F., Pascal, N., Tanré, D., Pelon, J., and Goloub, P. (2017). Consistency of aerosols above clouds characterization from A-Train active and passive measurements, Atmos. Meas. Tech., doi: 10.5194/amt-10-3499-2017.

[46] Peers, F., Francis, P., Fox, C., Abel, S., Szpek, K., Cotterell, M, Davies, N., Justin M. Langridge, J., Meyer, K. Platnick, E. and Haywood, J. (2019). Observation of absorbing aerosols above clouds over the south-east Atlantic Ocean from the geostationary satellite SEVIRI - Part 1: Method description and sensitivity, Atmos. Chem. Phys., 19, 9595-9611, doi: 10.5194/acp-19-9595-2019.

[47] Mukai, S., Sano, I. and Nakata, M. (2019). Efficient algorithms for aerosol retrieval from GCOM-C/SGLI", Proc. IGARSS 2019, Atmosphere Applications: Aerosols and Atmospheric Chemistry, 7614-7617.

[48] Sano, I. and Mukai, S. (2019) Detection of dense biomass burning area and the particle properties from GCOM-C / SGLI measurements", 2nd APOLO meeting, 2019/11/4-7 in Lille, France.

[49] Mukai, S., Sano, I. and Nakata, M. (2020) Effective characterization of aerosols in severe events using multi-channel measurements including polarization with GCOM-C/SGLI, Proc. SPIE 2020 (in press). 